\title{
The Existence of Cellulose and Lignin Chemical Connections in Ginkgo Traced by ${ }^{2} \mathrm{H}-{ }^{13} \mathrm{C}$ Dual Isotopes
}

\begin{abstract}
Yimin Xie, ${ }^{\mathrm{a}, \mathrm{b}, *}$ Yanchao Liu, ${ }^{\mathrm{a}}$ Chen Jiang, ${ }^{\mathrm{a}}$ Hongfei $\mathrm{Wu},{ }^{\mathrm{a}}$ and Shuying Bi ${ }^{\mathrm{a}}$
To elucidate the covalent association between the celluloses and lignins found in gymnosperms, they were labeled with stable isotopes (deuterium and carbon-13) at specific positions and traced via mass spectroscopy and nuclear magnetic resonance (NMR). Both the ${ }^{2} \mathrm{H}$-labeled cellulose precursor (UDP-glucose-[6- $\left.{ }^{2} \mathrm{H}_{2}\right]$ ) and the ${ }^{13} \mathrm{C}$-labeled lignin precursor (coniferin- $\left[\alpha-{ }^{13} \mathrm{C}\right]$ ) were added to a growing ginkgo plant, in combination with a 4-coumarate-CoA ligase inhibitor. The detection of abundance of ${ }^{13} \mathrm{C}$ and ${ }^{2} \mathrm{H}$ revealed that the lignin precursor and cellulose precursor deposited more actively in 300 to $1300 \mu \mathrm{m}$ and 100 to $900 \mu \mathrm{m}$ distance from cambium, respectively. The lignin-carbohydrate complexes (LCCs) were isolated from the newly-formed ginkgo shoot xylem and further degraded with cellulase and hemicellulase to obtain enzymatically degraded lignin-carbohydrate complexes (EDLCCs). Analysis of the solidstate cross polarization / magic angle spinning (CP/MAS) ${ }^{13} \mathrm{C}-\mathrm{NMR}$ of the newly-formed xylem, liquid-state ${ }^{13} \mathrm{C}-\mathrm{NMR}$, and ${ }^{1} \mathrm{H}-\mathrm{NMR}$ of the EDLCCs confirmed that the major connection between celluloses and lignins was a benzyl ether bond (between cellulose $\mathrm{C} 6$ and lignin $\mathrm{C} \alpha$ ). A minor ester bond was also found between the hydroxyl group (at the 6-position of cellulose) and ferulic acid (at the y position in lignins).
\end{abstract}

Keywords: Lignin-cellulose complexes; Isotope tracer; Ginkgo; NMR; Benzyl ether linkage

Contact information: a: Research Institute of Pulp \& Paper Engineering, Hubei University of Technology, Wuhan 430068 China; b: Hubei Provincial Key Laboratory of Green Materials for Light Industry, Hubei University of Technology, Wuhan 430068 China; *Corresponding author: ppymxie@163.com

\section{INTRODUCTION}

There are chemical bonds between the celluloses and lignins found in plant cell walls, which severely hinders the complete removal of lignins during the pulping process (Karlsson et al. 2001; Oinonen et al. 2015). This results in the consumption of an increased amount of chemicals and energy during the pulping and bleaching process (Daljeet $e t a l$. 2019; Sharma et al. 2020). In the 1990s, Karlsson and Westermark (1996) used chromatographic methods to prove that there was a strong lignin-cellulose chemical bond in pine kraft pulp. Isogai (2001) found that pure cellulose could not be obtained through repeated refining treatments when studying high-purity viscose cellulose; rather, it was usually accompanied by lignin components. Therefore, Isogai (2001) suggested that there might be a chemical bond between cellulose and lignins. Through endoglucanase-catalyzed hydrolysis and repeated purification, it was found that less than $10 \%$ of the lignincarbohydrate complexes (LCCs) in unbleached kraft softwood pulp had a linkage between the lignins and celluloses (Lawoko et al. 2003). Du et al. (2013) carried out deep delignification of pulp through a laccase-mediator and found that lignins always existed in the form of a glucan-lignin complex after deep treatment. Some researchers have also shown that there might be phenylglycoside bonds in the lignin-cellulose complexes (Kondo 
and Sarkanen 1984; Joseleau and Kesraoui 1986).

As an important method for studying the biosynthetic pathways, structures, and reaction mechanisms of polymers, isotope labeling technology has been widely used in the study of lignin-carbohydrate complexes (Ong et al. 2002; Tugarinov et al. 2006). Imai and Terashima (1990) made use of the cellulose precursor of D-glucose-[U- $\left.{ }^{14} \mathrm{C}\right]$ and a phenylalanine amonia-lyase (PAL) inhibitor to visualize the deposition process of cellulose. Xie et al. (2000) injected coniferin with ${ }^{13} \mathrm{C}$-labeled at the $\alpha, \beta$, and $\gamma$-positions of side chain into growing ginkgo to separate the LCC and the enzymatically degraded LCC. By this means they found that there were benzyl ether linkages, benzyl ester bonds, and acetal bonds. $\mathrm{Gu}(2002 \mathrm{a})$ also synthesized a ${ }^{13} \mathrm{C}$-labeled lignin precursor and injected it into the growing internode tissue of rice, so that the side chain of the lignin of rice straw was labeled with ${ }^{13} \mathrm{C}$ and the chemical structure of the lignin-carbohydrate complexes could be elucidated. Zhou et al. (2001) used the natural abundance of the stable isotope ratio $\left({ }^{18} \mathrm{O} /{ }^{16} \mathrm{O}\right)$ to analyze the chemical bonds between the celluloses and lignins in the plant cell walls and found $\gamma$-ester bonds and $\alpha$-ether bonds between the lignins and celluloses. Yang et al. (2007) put ${ }^{13} \mathrm{C}$-labeled coniferin into natural plant rice straw and analyzed it with high-resolution liquid ${ }^{13} \mathrm{C}-\mathrm{NMR}$ and found that the lignins were associated with cellulose and hemicellulose by benzyl ether connections. The above results indicated that there were chemical connections between the lignins and celluloses. However, the formation mechanism, the proportion of linkages, and the position of the bond have not yet been described.

In this study, the ${ }^{2} \mathrm{H} /{ }^{13} \mathrm{C}$ dual stable-isotope-labeling method was used to trace both the celluloses and lignins, as a means to determine the association between the celluloses and lignins found in the ginkgo tree. A cellulose precursor (UDP-glucose- $\left[6-{ }^{2} \mathrm{H}_{2}\right]$ ) and lignin precursor (coniferin- $\left[\alpha-{ }^{13} \mathrm{C}\right]$ ) were added to the ginkgo plant, and the levels of ${ }^{13} \mathrm{C}$ and ${ }^{2} \mathrm{H}$ were determined by elemental analysis combined with isotopic mass spectroscopy to understand the deposition of celluloses and lignins and elucidate the distribution of isotopic abundance in the newly-formed xylem. The possibility of conversion of the UDPglucose- $\left[6-{ }^{2} \mathrm{H}_{2}\right]$ to hemicellulose was also investigated. The newly-formed xylem with relatively high isotopic abundance was determined via $\mathrm{CP} / \mathrm{MAS}{ }^{13} \mathrm{C}-\mathrm{NMR}$. The milled wood lignin (MWL), lignin-carbohydrate complexes (LCCs), and enzymatically degraded LCCs (EDLCCs) labeled with $6-{ }^{2} \mathrm{H} / \alpha_{-}{ }^{13} \mathrm{C}$ were isolated from the newly-formed xylem of the ginkgo tree, and these were analyzed via ${ }^{13} \mathrm{C}-\mathrm{NMR}$ and ${ }^{1} \mathrm{H}-\mathrm{NMR}$ to determine the cellulose-lignin linkages of ginkgo. The proposed metabolic map of the present work is shown in Fig. 1. The 4CL inhibitor prevented the conversion of glucose to lignin, while coniferin- $\left[\alpha-{ }^{13} \mathrm{C}\right]$ was hydrolyzed into coniferyl alcohol by $\beta$-glucosidase.

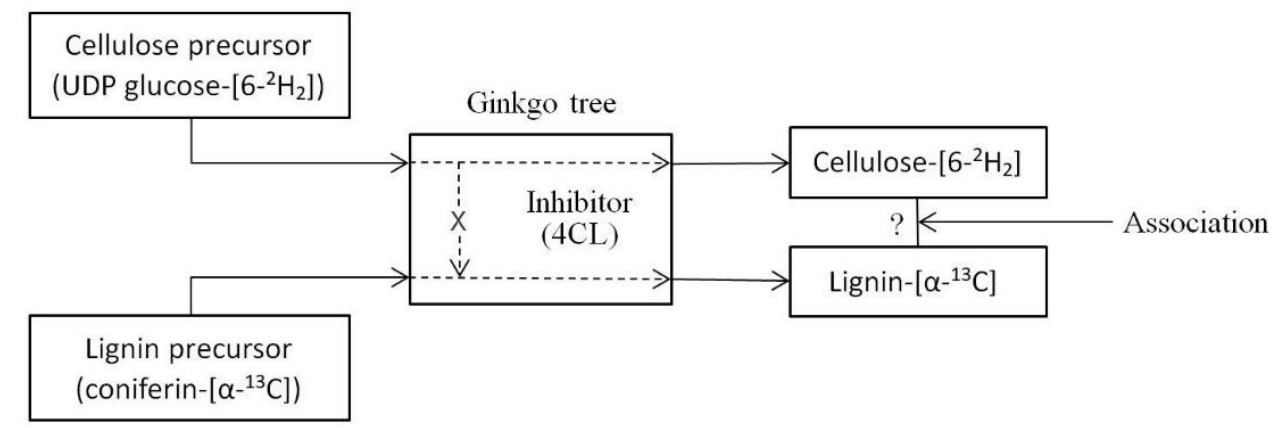

Fig. 1. The proposed metabolism route of the isotope labeled cellulose precursor and lignin precursor in a ginkgo tree

Xie et al. (2020). "Cellulose-lignin chemical bonds," BioResources 15(4), 9028-9044. 
Then the coniferyl alcohol was further converted to lignin, as shown in Fig. 2. Therefore, the lignin content in the ginkgo shoots administered with the coniferin was similar to that of intact ginkgo tree.



Fig. 2. Inhibiting of glucose transformation to lignin and metabolism of coniferin-[ $\left[\alpha^{13} \mathrm{C}\right]$

\section{EXPERIMENTAL}

\section{Materials}

Five-year-old Ginkgo biloba L. trees were obtained from the Wuhan Botanical Garden (Wuhan, China). Sodium acetate- $1-{ }^{13} \mathrm{C}$ and $\left(6-{ }^{2} \mathrm{H}_{2}\right)$ D-glucose were purchased from Sigma-Aldrich (Saint Louis City, MO), and 3,4-(methylenedioxy)cinnamic acid was purchased from Aladdin (Shanghai City, China). All other chemicals were analytical grade.

\section{Synthesis of the Isotope-Labeled Lignin and Cellulose Precursors}

Coniferin- $\left[\alpha-{ }^{13} \mathrm{C}\right]$ was synthesized using sodium acetate- $1-{ }^{13} \mathrm{C}$ according to previously described methods (Xie et al. 1994a,b). The cellulose precursor uridine diphosphoglucose-[6- $\left.{ }^{2} \mathrm{H}_{2}\right]$ was synthesized as previously described by Dinev et al. (2006). The chemical structures of the isotope enrichment precursors are shown in Fig. 3.
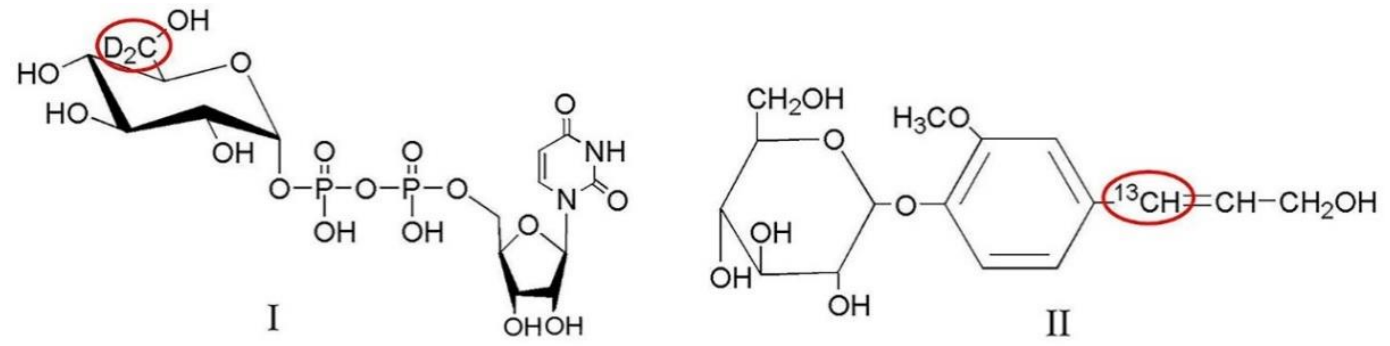

Fig. 3. Chemical structures of UDP glucose-[6- $\left.{ }^{2} \mathrm{H}_{2}\right](\mathrm{I})$ and coniferin- $\left[\mathrm{\alpha}^{-13} \mathrm{C}\right](\mathrm{II})$

\section{Administration of the Precursors to the Ginkgo Tree}

In early June, the five-year-old ginkgo tree was cut into shoots with a length of approximately $30 \mathrm{~cm}$, and 20 to 30 leaves were retained on each shoot. The culture solution of three ginkgo shoots was composed of UDP-glucose-6,6-D2 $(100 \mathrm{mg} / 100 \mathrm{~mL})$, coniferin-

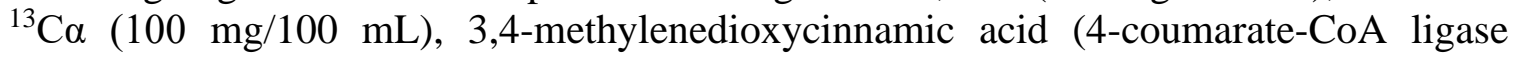


inhibitor) (10 mg /100 mL) constitute the experimental group. The culture solution of the other two ginkgo shoots consisted of unlabeled UDP-glucose $(100 \mathrm{mg} / 100 \mathrm{~mL})$, unlabeled coniferin $(100 \mathrm{mg} / 100 \mathrm{~mL})$, and 3,4-methylenedioxycinnamic acid $(10 \mathrm{mg} / 100 \mathrm{~mL})$, which served as the control group. The shoots were cultivated in an artificial climate chamber at $25{ }^{\circ} \mathrm{C}$ for $30 \mathrm{~d}$. The samples were kept in the light time and the dark time for $15 \mathrm{~h}$ and $9 \mathrm{~h}$ every day, respectively. When the precursor solution was completely absorbed, distilled water was added to the ginkgo plant.

\section{Determination of ${ }^{13} \mathrm{C}$ and ${ }^{2} \mathrm{H}$ Abundance}

The cut ginkgo shoots that were administered with both ${ }^{13} \mathrm{C}$-enriched coniferin and ${ }^{2} \mathrm{H}$-enriched UDP-glucose were debarked and cut into pieces $2.0 \mathrm{~cm}$ long, which were then cut into $100-\mu \mathrm{m}$-thick sections on a sliding microtome from cambium to pith, according to Terashima et al. (1979), as shown in Fig. 4.
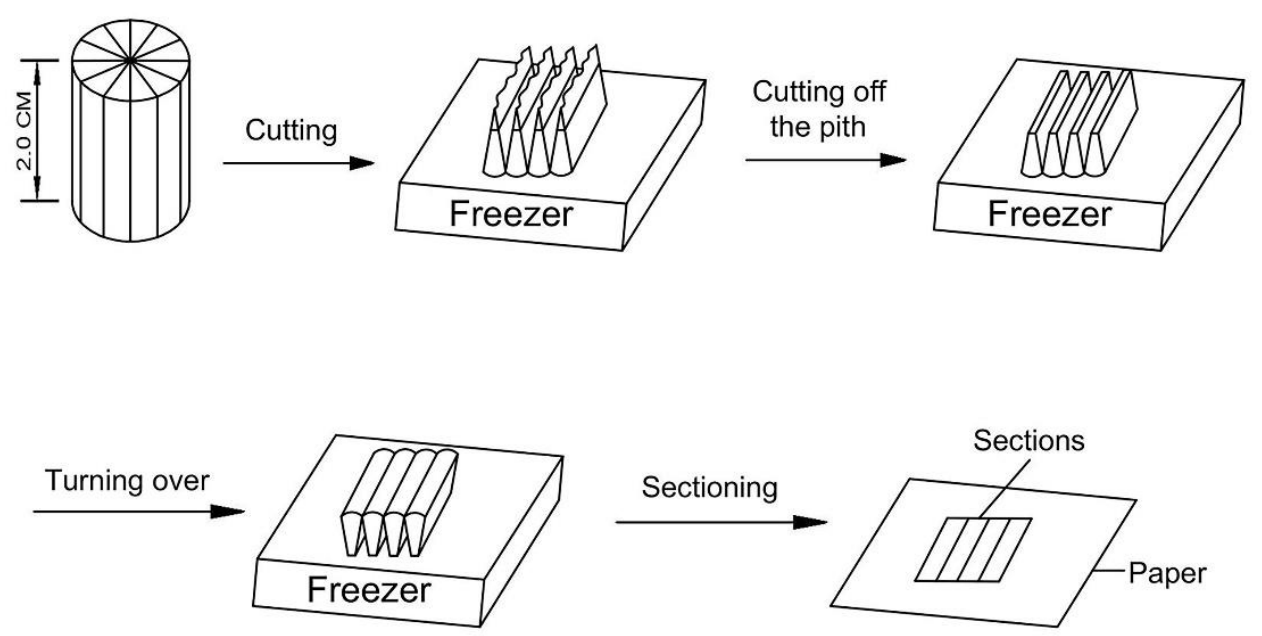

Fig. 4. Preparation of the tangential sections via a freezing microtome

The air-dried xylem sections were milled (40 mesh to 60 mesh) and extracted with ethanol-benzene $(1 / 2, v / v)$, followed by hot water. The $\mathrm{C}$ isotope value $\delta^{13} \mathrm{C}$ (Vienna Pee Dee Belemnite (VPDB)) and the H isotope value $\delta \mathrm{D}$ (VSMOW, Vienna Standard Mean Ocean Water) of $1 \mathrm{mg}$ of the extractive-free wood meal samples were measured via an elemental analyzer (FLASH2000, Thermo Fisher Scientific GmbH, Dreieich, Germany) combined with an isotope ratio mass spectrometer (Delta V, Thermo Fisher Scientific $\mathrm{GmbH}$, Dreieich, Germany), respectively. The ${ }^{13} \mathrm{C} /{ }^{12} \mathrm{C}$ and ${ }^{13} \mathrm{C} \alpha /{ }^{12} \mathrm{C} \alpha$ values in the sample were calculated using Eqs. 1 and 2,

$$
\begin{aligned}
& { }^{13} \mathrm{C} /{ }^{12} \mathrm{C}=1.105765 \% \times\left(1+\delta^{13} \mathrm{C} \div 1000\right) \\
& { }^{13} \mathrm{C} \alpha /{ }^{12} \mathrm{C} \alpha=1.0762 \%+\left({ }^{13} \mathrm{C} /{ }^{12} \mathrm{C}-1.0762 \%\right) \div 0.3 \times 9
\end{aligned}
$$

where ${ }^{13} \mathrm{C} /{ }^{12} \mathrm{C}$ is the ratio of ${ }^{13} \mathrm{C}$ to ${ }^{12} \mathrm{C}$ in the sample, $\delta^{13} \mathrm{C}$ is the $\mathrm{C}$ isotope value of the sample $\delta^{13} \mathrm{C}$ (VPDB) (\%), $1.105765 \%$ is the ${ }^{13} \mathrm{C}$ isotope abundance of the standard (Vienna Pee Dee Belemnite), ${ }^{13} \mathrm{C} \alpha /{ }^{12} \mathrm{C} \alpha$ is the ${ }^{13} \mathrm{C}$ and ${ }^{12} \mathrm{C}$ isotopic ratios of $\mathrm{C} \alpha$ in the lignin structural units of the sample, $1.0762 \%$ is the ${ }^{13} \mathrm{C}$ isotope values in intact ginkgo wood, 0.3 is the lignin content in a ginkgo plants, and 9 is the ratio of the number of total carbons to $\mathrm{C} \alpha$ in the lignin structures. 
The D/H and D6/H6 values in the samples were calculated using Eqs. 3 and 4,

$$
\begin{aligned}
& \mathrm{D} / \mathrm{H}=0.015575 \% \times(1+\delta \mathrm{D} \div 1000) \\
& \mathrm{D} 6 / \mathrm{H} 6=0.013505 \%+(\mathrm{D} / \mathrm{H}-0.013505 \%) \div 0.50 \times 5
\end{aligned}
$$

where $\mathrm{D} / \mathrm{H}$ is the ratio of $\mathrm{D}$ to $\mathrm{H}$ in the sample, $\delta \mathrm{D}$ is the $\mathrm{H}$ isotope value of the sample $\delta \mathrm{D}$ (VSMOW) (\%o), $0.015575 \%$ is the D isotope abundance of the standard (Vienna Standard Mean Ocean Water), D6/H6 is the isotope ratio of D to $\mathrm{H}$ in cellulose at position 6 in the sample, $0.013505 \%$ is the $\mathrm{D}$ isotopic value in intact ginkgo plants, 0.50 is the cellulose content in a ginkgo plant, and 5 is the ratio of the number of total hydrogens to H6 in the cellulose structures.

\section{Preparation of the Enzymatically Degraded Lignin-Carbohydrate Complexes (EDLCCs)}

Extractive-free wood meal (20 mesh) of the newly-formed xylems (300 $\mu \mathrm{m}$ to 900 $\mu \mathrm{m}$ from the cambium) from the cut ginkgo shoots were milled to a 80 mesh to 100 mesh size via a Wiley mill and then dried over phosphorus pentoxide for $7 \mathrm{~d}$ in a vacuum desiccator. Then, after $72 \mathrm{~h}$ of water-cooled vibration ball milling, the LCCs were extracted using methodology described by Björkman and Anders (1957). The LCC yield was $13.8 \%$ from the isotope-enriched ginkgo wood meal and $14.1 \%$ from the unlabeled ginkgo wood meal.

Five hundred milligrams of cellulase (Onozuka RS, Yakult Co., Japan) and $500 \mathrm{mg}$ of hemicellulase (from Aspergillus niger, Sigma-Alrich, St. Louis, MO) were dissolved in $50 \mathrm{ml}$ of $0.05 \mathrm{M}$ acetic acid/sodium acetate buffer (a pH of 4.6) and filtrated with a G4 glass filter. The enzyme solution was stored at $5{ }^{\circ} \mathrm{C}$. Then, The LCCs $(600 \mathrm{mg})$ were mixed with $16 \mathrm{~mL}$ of the enzyme solution and $24 \mathrm{~mL}$ of $0.05 \mathrm{M}$ acetic acid/sodium acetate buffer. Three drops of toluene were added as a protective agent. The mixture was cultured in a water baths shaker at $50{ }^{\circ} \mathrm{C}$ for $48 \mathrm{~h}$. The EDLCCs were collected via centrifugation, washed four times with water, and then freeze-dried.

\section{Extraction of Hemicellulose from the Newly-formed Xylem and Determination of ${ }^{2} \mathrm{H}$ Abundance}

Ginkgo wood meal labeled with ${ }^{2} \mathrm{H} /{ }^{13} \mathrm{C}$ was extracted with a mixture of benzene and ethanol in a volume ratio of $2: 1$. Then, the dried sample was extracted with $8 \% \mathrm{NaOH}$ solution at a solid-liquid ratio of $1: 20$ for $12 \mathrm{~h}$ at $80{ }^{\circ} \mathrm{C}$. After the extraction, the mixture was filtrated. The $\mathrm{pH}$ value of the filtrate was adjusted to 5.5 with the diluted $\mathrm{HCl}$ solution, and $95 \%$ ethanol solution with 3 times the volume of filtrate was added, and centrifuged. The precipitate was washed with $70 \%$ ethanol solution. The extracted hemicellulose was obtained by freeze-drying, and its ${ }^{2} \mathrm{H}$ abundance was determined.

\section{High-resolution Cross Polarization/Magic Angle Spinning (CP/MAS) ${ }^{13} \mathrm{C}-$ Nuclear Magnetic Resonance (NMR) Determination}

An Avance III 600-MHz solid-state NMR spectrometer with a solid probe (Bruker, Billerica, MA) was used. The experimental conditions were as follows: a temperature of $25{ }^{\circ} \mathrm{C}$, a $3 \mathrm{~ms}$ contact time, a $0.05 \mathrm{~s}$ reception time, a pulse width of $35 \mathrm{kHz}$, and a pulse delay of 2 s. Each sample was accumulated approximately 5000 times. 


\section{${ }^{13} \mathrm{C}$ - and ${ }^{1} \mathrm{H}-\mathrm{NMR}$ Spectra of the EDLCCs}

First, $80 \mathrm{mg}$ of the product was placed in a $\varphi 5-\mathrm{mm}$ NMR tube, and $0.5 \mathrm{~mL}$ of DMSO-d 6 solvent was added to dissolve it. All NMR spectra were recorded on a Bruker Avance III 500-MHz spectrometer equipped with a $\varphi 5 \mathrm{~mm}$ broad band fluorine observation (BBFO) probe at a temperature of $25{ }^{\circ} \mathrm{C}$. The ${ }^{13} \mathrm{C}$-NMR spectrum was recorded with the following conditions: a pulse delay of $2.6 \mathrm{~s}$ and a reception time of $0.94 \mathrm{~s}$, while data points were collected at $32 \mathrm{kbit}$ and after the accumulation of 7168 scans. The ${ }^{1} \mathrm{H}-\mathrm{NMR}$ spectrum was recorded with following conditions: a pulse delay of $4.3 \mathrm{~s}, 500$ scans, and an acquisition time of $0.74 \mathrm{~s}$, while the data points were collected at $32 \mathrm{kbit}$.

\section{RESULTS AND DISCUSSION}

\section{Analysis of the Abundance and Distribution of ${ }^{13} \mathrm{C}$ and ${ }^{2} \mathrm{H}$ in the Newly- formed Xylem}

Figure 5 shows the distribution of ${ }^{13} \mathrm{C}$ (derived from coniferin- $\left[\alpha-{ }^{13} \mathrm{C}\right]$ ) in the newly-formed ginkgo tree xylem. It can be found from Fig. 5 that the ${ }^{13} \mathrm{C} /{ }^{12} \mathrm{C}$ value of $\mathrm{C} \alpha$ of the lignin side chain was higher in the area 300 to $1300 \mu \mathrm{m}$ away from the cambium, indicating that the lignification was more active in this area. Terashima and Seguchi labeled the newly-formed xylem of pine with coniferin-( side chain $\alpha-{ }^{13} \mathrm{C}$ ) and found the increase of ${ }^{13} \mathrm{C} /{ }^{12} \mathrm{C}$ was high in the region of 200 to $700 \mu \mathrm{m}$ distant from the cambium (Terashima et al. 1991). The fact that the formation of lignin was most active in that region has been also shown by microautoradiography of differentiating xylem of pine (Terashima et al. 1988; Donaldson 2001). In the present research, the maximum ${ }^{13} \mathrm{C} /{ }^{12} \mathrm{C}$ value of $\mathrm{C} \alpha$ of the lignin side chain was $3.43 \%$, which indicated that the $\alpha-{ }^{13} \mathrm{C}$ abundance was 3.2 times higher than the natural abundance $\left({ }^{13} \mathrm{C} /{ }^{12} \mathrm{C}: 1.05765 \%\right)$.

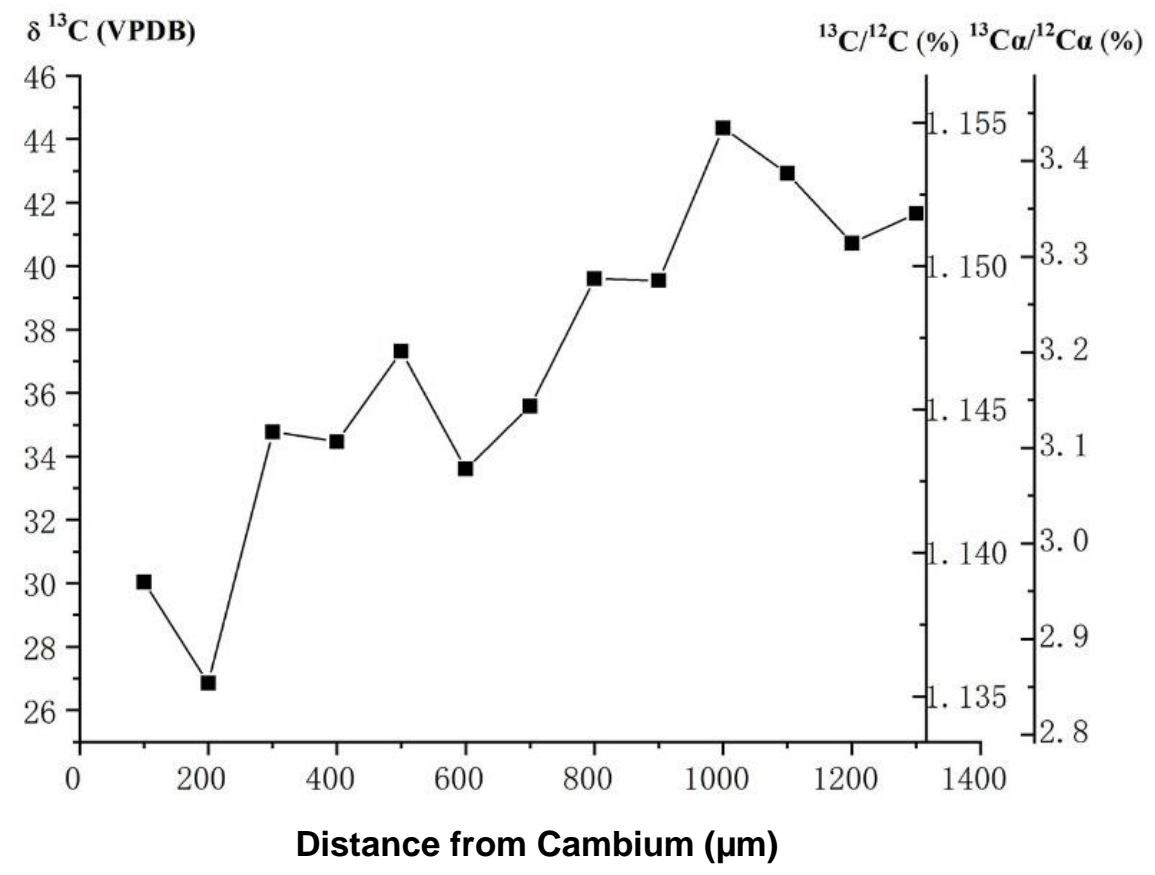

Fig. 5. The ${ }^{13} \mathrm{C}$ abundance in the newly-formed ginkgo xylem labeled by ${ }^{2} \mathrm{H}-{ }^{13} \mathrm{C}$ dual isotopes 
The result of hemicellulose abundance determination showed that the $\delta \mathrm{D}$ (VSMOW) value was $-83.257 \%$ determined by mass spectroscopy, which was close to natural abundance of plant composition, while the $\delta \mathrm{D}(\mathrm{VSMOW})$ value of the labeled ginkgo newly-formed xylem reached 266.523 to $290.671 \%$, as shown in Fig. 6. Therefore, the authors suggest that deuterium in the culture solution was mainly deposited in cellulose and the deposition of $\mathrm{D}$ in hemicellulose can be ignored. It is suggested that there was no pathway for conversion of UDP glucose-[6- $\left.{ }^{2} \mathrm{H}_{2}\right]$ to glucuronoxylan and glucomannan. Almost all of the deuterium isotope was involved in cellulose units.

It can be found from the Fig. 6 that the value of $\mathrm{D} / \mathrm{H}$ was higher in the region 100 to $900 \mu \mathrm{m}$ distance from the cambium, indicating that D was mainly deposited on the cellulose in this region. In the investigation of depositing stages of polysaccharide, Imai and Terashima labeled xylan in newly-formed xylem with myo-inositol- $\left(2-{ }^{3} \mathrm{H}\right)$, and found that xylan mainly deposited in the following two stages: (1) start of $\mathrm{S}_{1}$ formation in the region of 100 to $200 \mu \mathrm{m}$ distance from the cambium; (2) start of $\mathrm{S}_{3}$ formation in the region of 400 to $500 \mu \mathrm{m}$ distance from the cambium. These regions were revealed by microautoradiography of the differentiating xylem (Imai and Terashima 1992). The maximum D6/H6 value of the cellulose main chain $\mathrm{H} 6$ was $0.0868 \%$, which revealed that the enrichment of D6 was 6.43 times higher than the natural abundance (D6/H6: 0.0135\%).

According to the analysis of the abundance of ${ }^{13} \mathrm{C}$ and ${ }^{2} \mathrm{H}$, the lignins and celluloses were successfully labeled in the ginkgo tree and the precursors were effectively metabolized in the plants and polymerized into macromolecules. The results were consistent with previous studies (Xie et al. 1991; Xiang et al. 2013). In order to increase the abundance of ${ }^{13} \mathrm{C}$ and ${ }^{2} \mathrm{H}$ in the EDLCC, $300 \mu \mathrm{m}$ to $900 \mu \mathrm{m}$ microtome sections, which were enriched with both ${ }^{13} \mathrm{C}$ and ${ }^{2} \mathrm{H}$, were used in the isolation process.

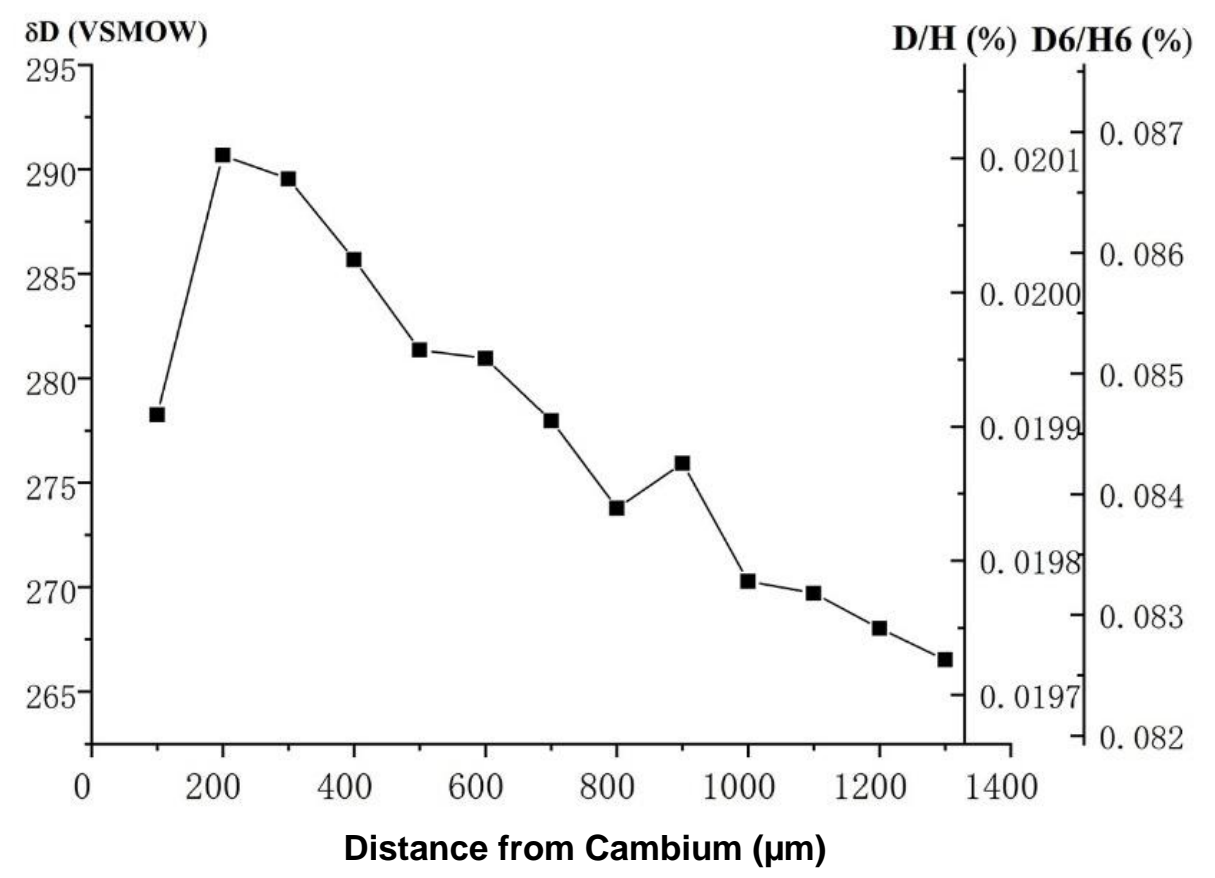

Fig. 6. The ${ }^{2} \mathrm{H}$ abundance in the newly-formed ginkgo xylem labeled by ${ }^{2} \mathrm{H}-{ }^{13} \mathrm{C}$ dual isotopes 


\section{Solid-state CP/MAS ${ }^{13} \mathrm{C}-\mathrm{NMR}$ Analysis of the $6-{ }^{2} \mathrm{H} / \mathrm{\alpha}-{ }^{13} \mathrm{C}$ Labeled Ginkgo Wood}

Solid-state magnetic resonance detection is used to study the structure of polymer compounds, e.g., the raw materials in paper (Bardet et al. 2002; Evstigneyev et al. 2018; Xue et al. 2019). Coniferin participates in the lignin biosynthesis process and does not interfere with the normal lignification of plants ( $\mathrm{Gu}$ et al. 2002b). To distinguish the isotope-labeled signals of the $\mathrm{C}$ atoms found in the lignin side chain from non-labeled ones, CP/MAS ${ }^{13} \mathrm{C}$ NMR differential spectroscopy was applied.

The CP/MAS ${ }^{13} \mathrm{C}-\mathrm{NMR}$ results of the newly-formed ginkgo xylem are shown in Fig. 7. The signal assignments are shown in Table 1 . The signals in the aliphatic region of the newly-formed xylem showed major enhancement, which indicated that the coniferin${ }^{13} \mathrm{C} \alpha$ could be converted into lignin moieties in ginkgo plants. The signals at $134.2 \mathrm{ppm}$ (No. 3') and $132.3 \mathrm{ppm}$ (No. 4') were from the $-\mathrm{C} \alpha=\mathrm{C}$ - in the coniferyl alcohol structure according to Lüdemann and Nimz (1973). The signals at 105 ppm (No. 5') could arise from the $\mathrm{C}-\alpha$ in the guaiacylpropane unit with a ketal linkage to carbohydrates, according to Jacques et al. (1974) and Xie et al. (2000). The No. 6' (88.3 ppm) and No. 7' (85.1 ppm) signals were drastically enhanced in the differential spectra, due to C- $\alpha$ enrichment, which could be assigned to $\mathrm{C}-\alpha$ in phenylcoumaran and $\mathrm{C}-\alpha$ in pinoresinol in lignin, respectively. Signal No. 8' (75.8 ppm) could be assigned to C- $\alpha$ in ferulic acid (lignins) with hydroxyl groups from carbohydrates according to Sipilä and Brunow (1991) and Xie et al. (2000). Carnachan et al. (2000) found that ferulic acid was bound to carbohydrates in the primary cell walls of 41 species of gymnosperms by using UV-fluorescence microscopy and gas chromatograph, and the contents of ferulic acid were $90 \mu \mathrm{g} / \mathrm{g}$ in ginkgo xylem treated with sodium hydroxide. Terashima et al. (2004) further found that the cross-linking of polysaccharides in ginkgo xylem was realized by free radical dimerization of ferulic acid polysaccharide esters. The signal at $73.2 \mathrm{ppm}$ (No. 9') was strong and broad, and it was related to the $\mathrm{C}-\alpha$ found in $\beta-\mathrm{O}-4$ structural units. This strong signal indicated that the $\beta$ O-4 structure was the dominant structure found in the ginkgo wood protolignin. This result was similar to the observations by Lewis et al. (1988) on ferulic acid- $\left[\alpha-{ }^{13} \mathrm{C}\right]$-labeled Leucaena leucocephala lignins. Signal No. 11' (63.1 ppm) arose from the C- $\alpha$ and C- $\beta$ in the $\beta-1$ structure found in the ginkgo lignin.

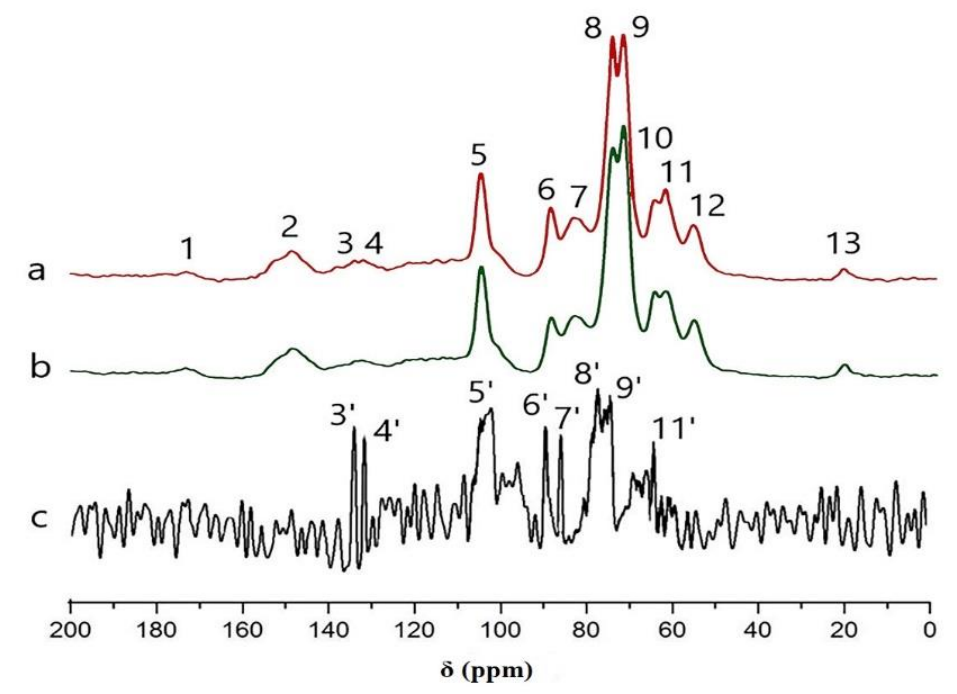

Fig. 7. Solid-state CP/MAS ${ }^{13} \mathrm{C}-N M R$ spectra of ginkgo wood meals: a - Newly-formed gingko xylem labeled with $6-{ }^{2} \mathrm{H} / \mathrm{a}^{-13} \mathrm{C}$; b - Intact newly-formed ginkgo xylem; and c - Differential spectrum obtained by subtracting spectrum (b) from spectrum (a) 
Table 1. CP/MAS ${ }^{13} \mathrm{C}-N M R$ Signal Analysis of Newly-Formed Ginkgo Xylem

\begin{tabular}{|c|c|c|c|c|}
\hline \multirow{2}{*}{ Signal } & \multicolumn{3}{|c|}{ Chemical Shifts $(\delta, \mathrm{ppm})$} & \multirow{2}{*}{ Assignments } \\
\hline & a & $b$ & $C$ & \\
\hline 1 & 173.1 & 173.3 & & $\begin{array}{l}\text { C-6 in uronic acid and esters, } \\
\mathrm{C}-\mathrm{\gamma} \text { in cinnamic acid and esters }\end{array}$ \\
\hline 2 & 149.8 & 148.7 & & C-3, C-4 in guaiacyl \\
\hline 3,3 & 134.2 & 134.4 & 134.2 & C- $\alpha$ in coniferyl alcohols \\
\hline $4,4^{\prime}$ & 132.3 & 132.6 & 132.3 & C- $\alpha$ in coniferyl alcohols \\
\hline 5,5 & 105.5 & 105.0 & 105.3 & $\begin{array}{c}\text { C-1 in celluloses, } \\
\text { C- } \alpha \text { in lignin bonded to carbohydrate with ketal linkages }\end{array}$ \\
\hline $6,6^{\prime}$ & 89.1 & 88.5 & 88.3 & $C-\alpha$ in $\beta-5$ \\
\hline $7,7^{\prime}$ & 83.7 & 84.6 & 85.1 & C- $\alpha$ in $\beta-\beta, C-4$ in celluloses, \\
\hline $8,8^{\prime}$ & 74.8 & 74.3 & 75.8 & $\begin{array}{l}\text { C- } \alpha \text { with ester linkage to carbohydrates, } \\
\text { C-2,3,5 in celluloses and hemicelluloses }\end{array}$ \\
\hline $9,9^{\prime}$ & 72.3 & 72.1 & 73.2 & $\mathrm{C}-\alpha$ in $\beta-\mathrm{O}-4$ \\
\hline 10 & 65.1 & 65.0 & & $C-\gamma$ and $C-\beta$ in $\beta-1$ \\
\hline $11,11^{\prime}$ & 62.1 & 62.2 & 63.1 & $\begin{array}{l}\text { C-6 in celluloses, } C-\gamma \text { in } \beta-O-4, C-\alpha, \\
\text { and C- } \beta \text { in } \beta-1\end{array}$ \\
\hline 12 & 56.0 & 56.1 & & $-\mathrm{OCH}_{3}$ \\
\hline 13 & 21.2 & 21.3 & & $-\mathrm{CH}_{3}$ \\
\hline
\end{tabular}

\section{Analysis of ${ }^{13} \mathrm{C}$-NMR Spectra of $\alpha-{ }^{13} \mathrm{C} / 6-{ }^{2} \mathrm{H}$-Enriched EDLCCs}

After the LCCs were hydrolyzed with cellulases and hemicellulases, most of the carbohydrates were hydrolyzed, which made information of the carbonyl region (160 ppm to $200 \mathrm{ppm})$ and the aliphatic region $(0 \mathrm{ppm}$ to $110 \mathrm{ppm})$ available. The remaining components after hydrolysis were primarily lignin macromolecules and carbohydrates covalently linked to the lignins. The ${ }^{13} \mathrm{C}-\mathrm{NMR}$ spectra of the $\alpha-{ }^{13} \mathrm{C} / 6-{ }^{2} \mathrm{H}$ EDLCCs and unlabeled EDLCCs are shown in Fig. 8, and the tentative assignments of the signals are shown in Table 2.

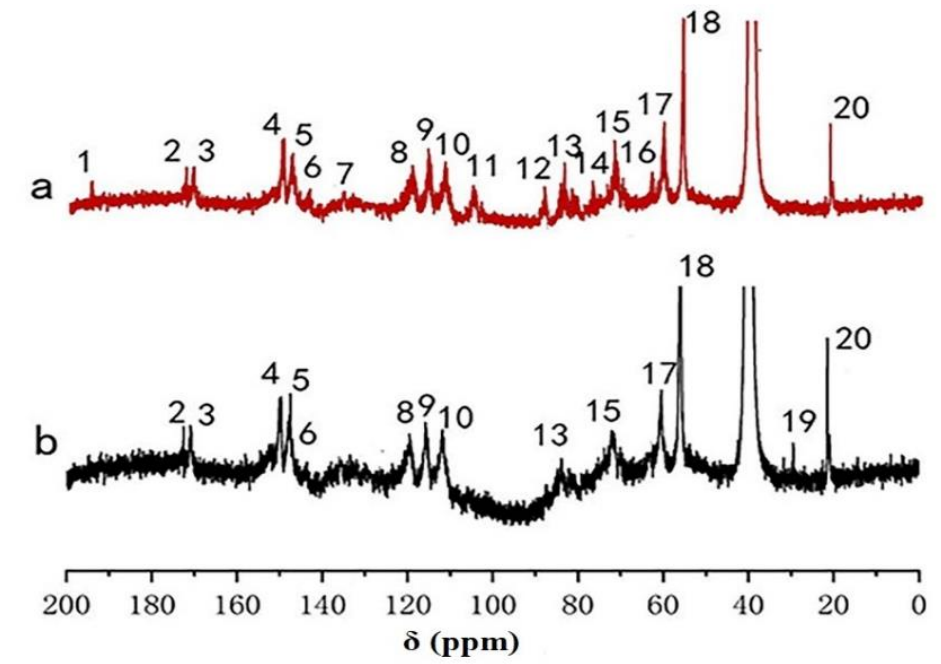

Fig. 8. The ${ }^{13} \mathrm{C}-N M R$ spectra of ginkgo EDLCCs: $a-a-{ }^{13} \mathrm{C} / 6-{ }^{2} \mathrm{H}$ labeled ginkgo EDLCCs; and $b$ unlabeled ginkgo EDLCCs

At $\delta 194.1 \mathrm{ppm}$ (No. 1), the labeled ginkgo EDLCCs were substantially enhanced compared to the unlabeled ginkgo EDLCCs, which was related to the ${ }^{13} \mathrm{C}$ labeling of the $\alpha-\mathrm{CO}$ in the vanillin found in the labeled ginkgo. The signal at $105.1 \mathrm{ppm}$ (No. 11) was 
enhanced by $\alpha-{ }^{13} \mathrm{C}$ labeling and was assigned to the ketal linkage between the $\mathrm{C}-\alpha$ of the lignin side chains and the carbohydrates The enhanced signal at $85.6 \mathrm{ppm}$ (No. 12) was the $\mathrm{C}-\alpha$ found in phenylcoumaran. The signal at $82.1 \mathrm{ppm}$ (No. 13) was obvious in the ${ }^{13} \mathrm{C}$ enriched EDLCCs and was assigned to the $\mathrm{C}-\alpha$ with an ether linkage to carbohydrates (Taneda et al. 1987; Xie et al. 2000) and the C- $\alpha$ signal found in pinoresinol. The signal at $76.1 \mathrm{ppm}$ (No. 14) was the $\mathrm{C}-\alpha$ with an ester linkage to carbohydrates. Signal No. 15 (72.2 ppm) was the $\mathrm{C}-\alpha$ in the $\beta-\mathrm{O}-4$ substructure.

From the above data, it was concluded that the lignins and carbohydrates found in the ginkgo LCCs are primarily connected by $\mathrm{C}-\alpha$ ether linkages, $\mathrm{C}-\alpha$ acetal bonds, and $\mathrm{C}$ $\alpha$ ester bonds.

Table 2. Chemical Shifts and Assignments of the ${ }^{13} \mathrm{C}-\mathrm{NMR}$ signals from the EDLCCs

\begin{tabular}{|c|c|c|c|}
\hline \multirow{2}{*}{ Signal } & \multicolumn{2}{|c|}{ Chemical Shifts (ppm) } & \multirow{2}{*}{ Assignments } \\
\hline & $\mathrm{a}$ & $b$ & \\
\hline 1 & 194.1 & - & $\begin{array}{c}\alpha-\mathrm{CO} \text { in vanillin, and } \\
\mathrm{y}-\mathrm{CHO} \text { in cinnamaldehyde }\end{array}$ \\
\hline 2 & 172.2 & 172.4 & $\begin{array}{l}\text { Cinnamic acid, and } \\
\text { acetyl }\end{array}$ \\
\hline 3 & 170.2 & 170.3 & $\begin{array}{l}\text { Cinnamic acid, and } \\
\text { acetyl }\end{array}$ \\
\hline 4 & 150.2 & 150.3 & $\begin{array}{l}\text { C-4 in guaiacyl with } \alpha \text { ether, and } \\
\text { C- } \alpha \text { in cinnamaldehyde }\end{array}$ \\
\hline 5 & 148.2 & 148.5 & $\begin{array}{l}\text { C-4 in guaiacyl, and } \\
\text { C-3 in guaiacyl }\end{array}$ \\
\hline 6 & 144.2 & 144.3 & C-4 in phenylcoumaran \\
\hline 7 & 135.1 & - & C- $\alpha$ in coniferyl alcohols \\
\hline 8 & 119.1 & 119.3 & C-6 in guaiacyl \\
\hline 9 & 115.2 & 115.4 & $\begin{array}{c}\text { C-6 in phenylcoumaran, and } \\
\text { C-5 in guaiacyl }\end{array}$ \\
\hline 10 & 111.3 & 111.4 & C-2 in guaiacyl \\
\hline 11 & 105.1 & - & $\begin{array}{l}\text { C- } \alpha \text { ketal linkage with carbohydrates, and } \\
\text { C-1 in cellulose }\end{array}$ \\
\hline 12 & 85.6 & - & C- $\alpha$ in phenylcoumaran \\
\hline 13 & 82.1 & 82.3 & $\begin{array}{c}\text { C- } \alpha \text { with ether linkage with carbohydrates, } \\
\text { C- } \alpha \text { in pinoresinol, } \\
\text { C- } \beta \text { in } \beta \text {-aryl ethers, and } \\
\text { C- } 4 \text { in celluloses }\end{array}$ \\
\hline 14 & 76.1 & - & $\begin{array}{l}\text { C- } \alpha \text { linked to carbohydrate ester bonds, and } \\
\text { C-2,3,5 in celluloses and hemicelluloses }\end{array}$ \\
\hline 15 & 72.2 & 72.3 & $\begin{array}{l}\text { C- } \alpha \text { in } \beta \text {-aryl ethers, and } \\
\text { C- } 2,3,5 \text { in celluloses }\end{array}$ \\
\hline 16 & 62.1 & - & $C-\alpha$ and $C-\beta$ in $\beta-1$ \\
\hline 17 & 60.1 & 60.2 & $\begin{array}{l}\text { C- } y \text { in } \beta \text {-aryl ethers, and } \\
\text { C-6 in celluloses }\end{array}$ \\
\hline 18 & 55.3 & 55.4 & $-\mathrm{OCH}_{3}$ \\
\hline 19 & - & 28.2 & Unknown \\
\hline 20 & 20.1 & 20.0 & $-\mathrm{CH}_{3}$ \\
\hline
\end{tabular}




\section{Analysis of the ${ }^{1} \mathrm{H}$-NMR Spectra of the $\alpha-{ }^{13} \mathrm{C} / 6-{ }^{2} \mathrm{H}$-enriched EDLCCs}

After enzymatic hydrolysis via cellulases and hemicellulases, many of the $\beta-1,4-$ glycosidic bonds between the glucose units in the cellulose macromolecules were broken; this made the chemical structure information between the lignin and cellulose units available. In the ${ }^{1} \mathrm{H}-\mathrm{NMR}$ differential spectrum (Fig. 9), cellulose 6-H was successfully labeled with ${ }^{2} \mathrm{H}$, and signals for the glucose units appeared. This showed that the $\alpha^{-13} \mathrm{C} /{ }^{2} \mathrm{H}-$ labeled EDLCCs contained ${ }^{2} \mathrm{H}$-labeled glucose units and that there was a chemical connection between the lignins and celluloses.

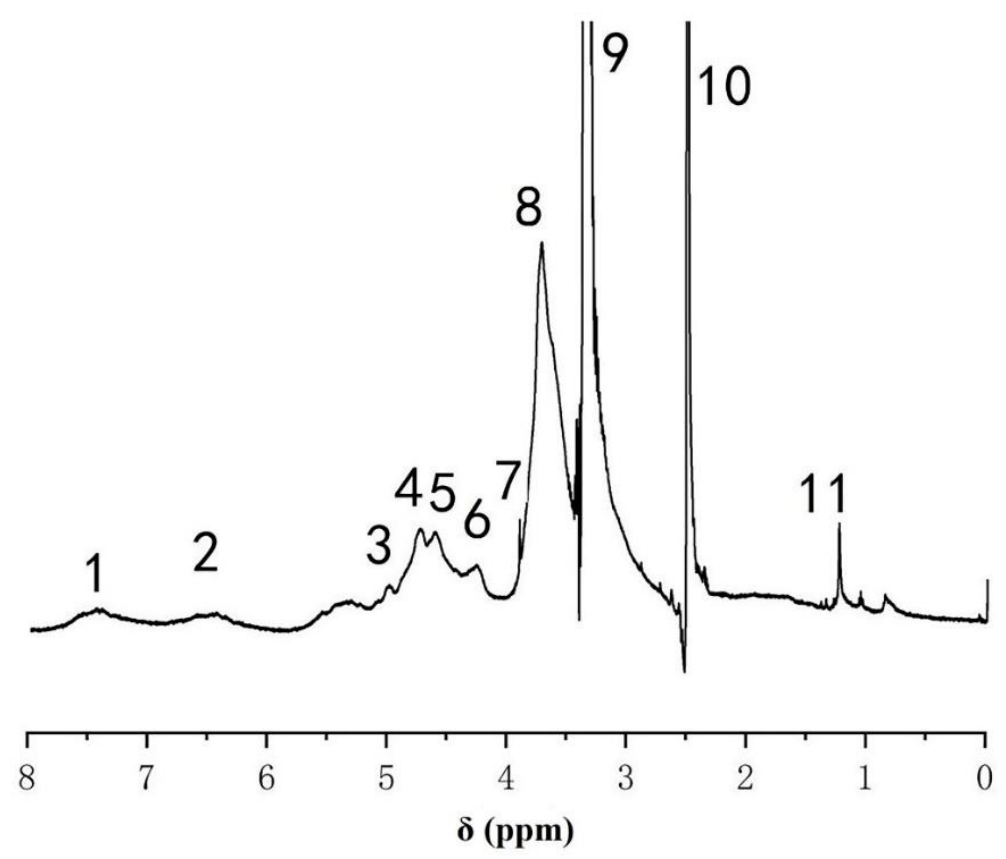

Fig. 9. The ${ }^{1} \mathrm{H}-\mathrm{NMR}$ differential spectrum of the EDLCCs from ginkgo wood obtained by subtracting spectrum $\alpha-{ }^{13} \mathrm{C} / 6-{ }^{2} \mathrm{H}$-labled EDLCC from the unlabeled spectrum

The vibration signals No. 4 (4.73 ppm) and No. 5 (4.65 ppm) were assigned to the 6-H and 6-H' found in benzyl 6-cellulose, according to the result of Nishida et al. (1984). This indicated the existence of an ether bond between the $\alpha$-position of lignins and the 6position of celluloses. The resonance signals at No. 6 (4.25 ppm) and No. 7 (3.91 ppm) were caused by the 6-H and 6-H' found in esterified cellulose (Deus et al. 1991; Hikichi et al. 1995). This result revealed that ester linkages were formed by hydroxyl groups on the 6-position of celluloses and the carboxyl group on $\gamma$-position of ferulic acid (lignins), also based the results of ${ }^{13} \mathrm{C}$-NMR determination of the milled wood lignin (MWL) from ginkgo xylem with ${ }^{13} \mathrm{C}$-enrichment of $\gamma$-position of lignin (unpublished). Since the strong signal at $3.75 \mathrm{ppm}$ (No. 8) was from the 6-H and 6-H' of the unsubstituted celluloses (Nishida et al. 1984), the hydroxyl groups on most cellulose molecular units in the ginkgo plant were unsubstituted. The assignments of the signals are listed in Table 3, and the structure of the cellulose-lignin complexes and related lignin substructures are shown in Fig. 10. 
<smiles>[R]Oc1ccc(C(O)C(CO)Oc2ccc(I)cc2OC)cc1OC</smiles>

$\beta-\mathrm{O}-4$<smiles>[R]Oc1ccc(C2OCC3C(c4ccc(O[Tl])c(OC)c4)OCC23)cc1OC</smiles>

$\beta-\beta$<smiles>[R]Oc1ccc(C2OC(CO)C(COc3ccc(I)cc3OC)OC2C2(C)CC3(C)CC2CO3)cc1OC</smiles>

C- $\alpha$ ether type LCC<smiles>[R]Oc1ccc(C2Oc3c(OC)cc(I)cc3C2CO)cc1OC</smiles>

$\beta-5$<smiles>[R]Oc1ccc(C(O)C(CO)c2ccc(O[Tl])c(OC)c2)cc1OC</smiles>

$\beta-1$

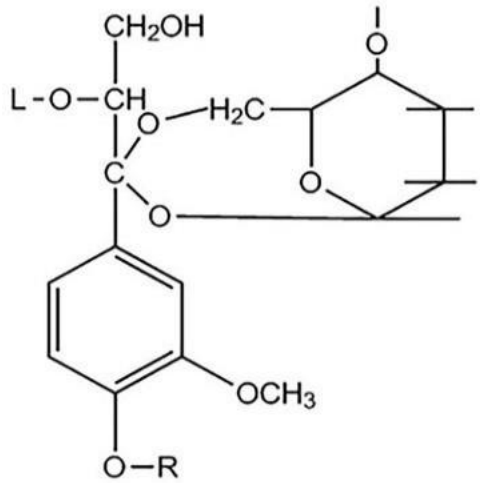

C- $\alpha$ ketal type LCC<smiles>COc1ccc(/C=C/C(=O)OCC2OC(OC)C3(C)CC2CC3OC)cc1OC</smiles>

C- $\gamma$ ester type LCC

(Cellulose; and Hemicellulose?) (Cellulose; and Hemicellulose?) (R=H or Polylignol; L=Polylignol)

Fig. 10. Lignin structural units and their connections with celluloses and hemicelluloses 
Table 3. Assignment of the Signals of the ${ }^{1} \mathrm{H}-\mathrm{NMR}$ Differential Spectrum of EDLCCs Obtained by Subtracting Spectrum $\alpha-{ }^{13} \mathrm{C} / 6-{ }^{2} \mathrm{H}$-labeled EDLCC from the Unlabeled EDLCC Spectrum

\begin{tabular}{|c|c|c|}
\hline Signal & Chemical Shifts (ppm) & Assignments \\
\hline 1 & 7.42 & $\mathrm{H}$ of the guaiacyl units of lignin structure \\
\hline 2 & 6.48 & $\alpha-\mathrm{H}$ in phenylpropane units of lignin \\
\hline 3 & 5.00 & $\alpha-\mathrm{H}$ and $\beta-\mathrm{H}$ in $\beta-5, \beta-0-4, \beta-1$ of lignin \\
\hline 4 & 4.73 & Benzyl cellulose $6-\mathrm{H}$ \\
\hline 5 & 4.65 & Benzyl cellulose $6-\mathrm{H}^{\prime}$ \\
\hline 6 & 4.25 & Ester-bonded cellulose 6-H \\
\hline 7 & 3.91 & Ester-bonded cellulose 6-H' \\
\hline 8 & 3.75 & Cellulose $6-\mathrm{H}, \mathrm{H}^{\prime}$ \\
\hline 9 & 3.31 & Water signal in DMSO- $\mathrm{d}_{6}$ solvent \\
\hline 10 & 2.50 & DMSO- $d_{6}$ solvent peak \\
\hline 11 & 1.25 & Highly obscured aliphatic $\mathrm{H}$ \\
\hline
\end{tabular}

\section{CONCLUSIONS}

1. Through the analyses of the abundance and distribution of ${ }^{13} \mathrm{C}$ and ${ }^{2} \mathrm{H}$ in the newlyformed xylem of ginkgo shoots, it was found that the deposition of ${ }^{13} \mathrm{C}$ on lignin was more active at 300 to $1300 \mu \mathrm{m}$ distance from the cambium and the deposition of $\mathrm{D}$ on cellulose was more active at 100 to $900 \mu \mathrm{m}$ distance from the cambium. The $6-{ }^{2} \mathrm{H} / \alpha-$ ${ }^{13} \mathrm{C}$ dual-labeled ginkgo wood was analyzed via solid-state CP/MAS ${ }^{13} \mathrm{C}$ NMR. The lignin structural units were primarily connected via the $\beta-\mathrm{O}-4, \beta-5, \beta-1$, and $\beta-\beta$ structures found in ginkgo plants with a minor coniferyl alcohol structure. Moreover, the $\mathrm{C}-\alpha$ in the lignin side chains were connected to carbohydrates through ketal linkages and ester linkages.

2. There were ether linkages and ketal linkages between the $\mathrm{C}-\alpha$ found in the lignin side chains and carbohydrates, as shown by ${ }^{13} \mathrm{C}$-NMR of the ${ }^{13} \mathrm{C}$-enriched enzymatically degraded LCC. The ${ }^{1} \mathrm{H}-\mathrm{NMR}$ differential spectrum of the $\alpha-{ }^{13} \mathrm{C} / 6-{ }^{2} \mathrm{H}$ dual-labeled and unlabeled EDLCC ginkgo wood samples showed a benzyl ether bond between the C-6 position of celluloses and the side chain $\alpha$-carbon of lignins. The results also revealed that ester linkages were formed by hydroxyl groups on the 6-position of cellulose and the $\gamma$-position of ferulic acid of lignin.

\section{ACKNOWLEDGMENTS}

The authors are grateful for the support of the National Natural Science Foundation of China (Grant No. 21878070), and Outstanding Young and Middle-aged Technological Innovation Team Project of Hubei Provincial Universities (Grant No. T201205). 


\section{REFERENCES CITED}

Bardet, M., Foray, M. F., and Tran, Q.-K. (2002). "High-resolution solid-state CPMAS NMR study of archaeological woods," Analytical Chemistry 74(17), 4386-4390. DOI: 10.1021/ac020145j

Björkman, A. (1957). "Lignin and lignin-carbohydrate complexes," Industrial \& Engineering Chemistry 49(9), 1395-1398. DOI: 10.1021/ie50573a040

Carnachan, S .M., and Harris, P. J. (2000). "Ferulic acid is bound to the primary cell walls of all gymnosperm families," Biochemical Systematics \& Ecology 28(9), 865879. DOI: 10.1016/S0305-1978(00)00009-0

Daljeet, K., Bhardwaj, N. K., and Kumar, L. R. (2019). "Effect of incorporation of ozone prior to ECF bleaching on pulp, paper and effluent quality," Journal of Environmental Management 236, 134-145. DOI: 10.1016/j.jenvman.2019.01.089

Deus, C., Friebolin, H., and Siefert, E. (1991). "Partiell Acetylierte Cellulose-Synthese und Bestimmung der Substituentenverteilung mit Hilfe der ${ }^{1} \mathrm{H}$ NMR Spektroskopie," [Partially acetylated cellulose - synthesis and determination of the distribution of substituents using 1 H NMR spectroscopy] Die Makromolekulare Chemie 192(1), 7583. DOI: $10.1002 / \mathrm{macp} .1991 .021920107$

Dinev, Z., Wardak, A. Z., Brownlee, R. T. C., and Williams, S. J. (2006). “A convenient gram-scale synthesis of uridine diphospho $\left({ }^{13} \mathrm{C}_{6}\right)$ glucose," Carbohydrate Research 341(10), 1743-1747. DOI: 10.1016/j.carres.2006.02.033

Du, X., Li, J., Gellerstedt, G., Rencoret, J., Del Río, J. C., Martínez, A. T., and Gutiérrez, A. (2013). "Understanding pulp delignification by laccase-mediator systems through isolation and characterization of lignin-carbohydrate complexes," Biomacromolecules 14(9), 3073-3080. DOI: 10.1021/bm4006936

Evstigneyev, E. I., Mazur, A. S., Kalugina, A. V., Pranovich, A. V., and Vasilyev, A. V. (2018). "Solid-state ${ }^{13} \mathrm{C}$ CP/MAS NMR for alkyl-O-aryl bond determination in lignin preparations," Journal of Wood Chemistry and Technology 38(2), 137-148. DOI: 10.1080/02773813.2017.1393436

Fukushima, K., and Terashima, N. (1991). "Heterogeneity in formation of lignin," Wood Science and Technology 25(5), 371-381. DOI: 10.1007/BF00226177

Funk, C., and Brodelius, P. E. (1990). "Phenylpropanoid metabolism in suspension cultures of Vanilla planifolia Andr. II. Effects of precursor feeding and metabolic inhibitors," Plant Physiology 94(1), 95-101. DOI: 10.1104/pp.94.1.95

Gu, R., Xie, Y., Zeng, S., Hong, W., and Yasuda, S. (2002b). "Carbon-13 enrichment of rice stalk lignin traced by solid state ${ }^{13} \mathrm{C}$ NMR spectroscopy," Chemical Journal of Chinese Universities 23(6), 1073-1076.

Gu, R., Xie, Y., Hong, W., and Lai Y. (2002a). "Carbon 13-enrichment of dehydrogenation polymers of monolignols traced by solidstate ${ }^{13} \mathrm{C}$ nuclear magnetic resonance" Chemistry and Industry of Forest Products 22(1), 1-6. DOI: 10.3321/j.issn:0253-2417.2002.01.001

Hikichi, K., Kakuta, Y., and Katoh, T. (1995). "'H NMR study on substituent distribution of cellulose diacetate," Polymer Journal 27(7), 659-663.

DOI: $10.1295 /$ polymj.27.659

Imai, T., and Terashima, N. (1990). "Determination of the distribution and reaction of polysaccharides in wood cell walls by the isotope tracer technique I. Selective radiolabeling of cell wall polysaccharides in Magnolia kobus," Mokuzai Gakkaishi 36(11), 917-922. 
Imai, T., and Terashima, N. (1992). "Determination of the distribution and reaction of polysaccharides in wood cell walls by the isotope tracer technique III. Visualization of the deposition and distribution of galacturonan in the cell walls of magnolia (Magnolia kobus DC.) xylem by microautoradiography," Mokuzai Gakkaishi 38(5), 475-481.

Isogai, A. (2001). Material Science of Cellulose, University of Tokyo Press, Tokyo, Japan.

Jacques, D., Haslam, E., Bedford, G. R., and Greatbanks, D. (1974). "Plant proanthocyanidins. Part II. Proanthocyanidin-A2 and its derivatives," Journal of the Chemical Society, Perkin Transactions 1 1974(0), 2663-2671. DOI: 10.1039/P19740002663

Joseleau, J.-P., and Kesraoui, R. (1986). "Glycosidic bonds between lignin and carbohydrates," Holzforschung 40(3), 163-168. DOI: 10.1515/hfsg.1986.40.3.163

Karlsson, O., Pettersson, B., and Westermark, U. (2001). "The use of cellulases and hemicellulases to study lignin-cellulose as well as lignin-hemicellulose bonds in kraft pulps," Journal of Pulp and Paper Science 27(6), 196-201.

Karlsson, O., and Westermark, U. (1996). "Evidence for chemical bonds between lignin and cellulose in kraft pulps," Journal of Pulp and Paper Science 22(10), J397-J401.

Kondo, R., and Sarkanen, K. V. (1984). "Kinetics of lignin and hemicellulose dissolution during the initial stage of alkaline pulping," Holzforschung 38(1), 31-36. DOI: 10.1515/hfsg.1984.38.1.31

Lawoko, M., Henriksson, G., and Gellerstedt, G. (2003). "New method for quantitative preparation of lignin-carbohydrate complex from unbleached softwood kraft pulp: Lignin-polysaccharide networks," Holzforschung 57(1), 69-74. DOI: 10.1515/HF.2003.011

Lewis, N. G., Razal, R. A., Dhara, K. P., Yamamoto, E., Bokelman, G. H., and Wooten, J. B. (1988). "Incorporation of $\left[2-{ }^{13} \mathrm{C}\right]$ ferulic acid, a lignin precursor, into Leucaena leucocephala and its analysis by solid state ${ }^{13} \mathrm{C}$ NMR spectroscopy," Journal of the Chemical Society, Chemical Communications 1988(24), 1626-1628. DOI: 10.1039/C39880001626

Lüdemann, H. D., and Nimz, H. H. (1973). “Carbon-13 nuclear magnetic resonance spectra of lignins," Biochemical and Biophysical Research Communications 52(4), 1162-1169. DOI: 10.1016/0006-291X(73)90622-0

Nishida, Y., Ohrui, H., and Meguro, H. (1984). "'H-NMR studies of (6r)- and (6s)deuterated D-hexoses: Assignment of the preferred rotamers about C5C6 bond of Dglucose and D-galactose derivatives in solutions," Tetrahedron Letters 25(15), 15751578. DOI: 10.1016/S0040-4039(01)90014-0

Oinonen, P., Zhang, L., Lawoko, M., and Henriksson, G. (2015). "On the formation of lignin polysaccharide networks in Norway spruce,” Phytochemistry 111, 177-184. DOI: 10.1016/j.phytochem.2014.10.027

Ong, S.-E., Blagoev, B., Kratchmarova, I., Kristensen, D. B., Steen, H., Pandey, A., and Mann, M. (2002). "Stable isotope labeling by amino acids in cell culture, SILAC, as a simple and accurate approach to expression proteomics," Molecular \& Cellular Proteomics 1(5), 376-386. DOI: 10.1074/mcp.m200025-mcp200

Sharma, N., Bhardwaj, N. K., and Singh, R. B. P. (2020). "Environmental issues of pulp bleaching and prospects of peracetic acid pulp bleaching: A review," Journal of Cleaner Production 256, 1-44. DOI: 10.1016/j.jclepro.2020.120338 
Sipilä, J., and Brunow, G. (1991). "On the mechanism of formation of non-cyclic benzyl ethers during lignin biosynthesis. Part 4 . The reactions of a $\beta-O-4$ type quinone methide with carboxylic acids in the presence of phenols. The formation and stability of benzyl esters between lignin and carbohydrates," Holzforschung 45(s1), 9-14. DOI: $10.1515 /$ hfsg. 1991.45.s1.9

Taneda, H., Nakano, J., Hosoya, S., and Chang, H.-M. (1987). "Stability of $\alpha$-ether type model compounds during chemical pulping processes," Journal of Wood Chemistry and Technology 7(4), 485-497. DOI: 10.1080/02773818708085281

Terashima, N., Fukushima, K., Sano, Y., and Takabe, K. (1988). "Heterogeneity in formation of lignin. X. Visualization of lignification process in differentiating xylem of pine by microautoradiography," Holzforschung 42(6), 347-350. DOI: 10.1515/hfsg.1988.42.6.347

Terashima, N., Okada, M., and Tomimura, Y. (1979). "Hetrogeneity in formation of lignin. I. Heterogeneous incorporation of p-hydrobenzoic acid into popular lignin," Mokizai Gakkaishi 25, 422-426.

Terashima, N., Seguchi, Y., and Robert, D. (1991). "Selective ${ }^{13} \mathrm{C}$ enrichment of side chain carbons of guaiacyl lignin in pine," Holzforschung 45(s1), 35-39. DOI: 10.1515/hfsg.1991.45.s1.35

Terashima, N., Awano, T., Takabe, K., and Yoshida, M. (2004). "Formation of macromolecular lignin in ginkgo xylem cell walls as observed by field emission scanning electron microscopy," Comptes Rendus Biologies 327(9-10), 903-910. DOI: 10.1016/j.crvi.2004.08.001

Tugarinov, V., Kanelis, V., and Kay, L. E. (2006). "Isotope labeling strategies for the study of high-molecular-weight proteins by solution NMR spectroscopy," Nature Protocols 1(2), 749-754. DOI: 10.1038/nprot.2006.101

Xiang, S.-M., Xie, Y.-M., Yang, H.-T., and Yao, L. (2013). "Analysis of the association between cellulose and lignin by carbon 13 tracer method," Spectroscopy and Spectral Analysis 33(9), 2488-2491. DOI: 10.3964/j.issn.1000-0593(2013)09-2488-04

Xie, Y., and Terashima, N. (1991). "Selective carbon 13-enrichment of side chain carbons of ginkgo lignin traced by carbon 13 nuclear magnetic resonance," Mokuzai Gakkaishi 37(10), 935-941.

Xie, Y., Yasuda, S., and Terashima, N. (1994a). "Selective carbon 13-enrichment of side chain carbons of oleander lignin traced by carbon 13 nuclear magnetic resonance," Mokuzai Gakkaishi 40(2), 191-198.

Xie, Y., Robert, D. R., and Terashima, N. (1994b). "Selective carbon 13 enrichment of side chain carbons of ginkgo lignin traced by carbon 13 nuclear magnetic resonance," Plant Physiology and Biochemistry 32(2), 243-249.

Xie, Y., Yasuda, S., Wu, H., and Liu, H. (2000). "Analysis of the structure of lignincarbohydrate complexes by the specific ${ }^{13} \mathrm{C}$ tracer method," Journal of Wood Science, 46(2), 130-136. DOI: 10.1007/BF00777359

Xue, K., Alex, K., Widanage, M. C. D., Frederic, M.-V., Cosgrove, D. J., and Wang, T. (2019). "Lignin-polysaccharide interactions in plant secondary cell walls revealed by solid-state NMR,” Nature Communications 10(1), 1-9. DOI: 10.1038/s41467-01808252-0

Yang, H., Xie, Y., Yao, L., and Wang, S. (2007). "On the lignin-carbohydrate association in rice stalk by the ${ }^{13} \mathrm{C}$ isotope tracer technique," Cellulose Chemistry and Technology 41(7-8), 363-369. 
Zhou, Y., Stuart-Williams, H., Farquhar, G. D., and Hocart, C. H. (2001). "The use of natural abundance stable isotopic ratios to indicate the presence of oxygen-containing chemical linkages between cellulose and lignin in plant cell walls," Phytochemistry 71(8-9), 982-993. DOI: 10.1016/j.phytochem.2010.03.001

Article submitted: June 19, 2020; Peer-review completed: August 3, 2020; Revised version received and accepted: October 6, 2020; Published: October 15, 2020.

DOI: 10.15376/biores.15.4.9028-9044 